\title{
CORRESPONDENCE
}

Intravenous $\mathbf{N}$-acetylcysteine: the treatment of choice in paracetamol poisoning?

J A Vale, MRCP, and others . . . . . . . 1435

Monitoring of psychotropic drug prescribing in general practice

D L Crombie, FRCGP........... 1436

Perinatal epidemiology in Wonderland Jean Golding, PHD; R G Newcombe, FSS. . 1436

Non-compliance: does it matter ?

T Pastor, MRCPSYCH. . . . . . . . . . . . 1437

Adverse reactions to drugs in general practice

Ann Cartwright, PHD............. 1437

Poisoning with chlormethiazole D B Scott, FFARCS. . . . . . . . . . . 1437

$A$ reminder to remind the patient N R Watson, Msc. . . . . . . . . . . . 1437

Confusion associated with cimetidine H G Kinnell, MRCPSYCH, and A Webb, MRCP .................... 1438

Neutropenia associated with metronidazole A $M$ Geddes, FRCPED, and $M$ W McKendrick, MRCP............ 1438
Fatal carbon monoxide poisoning-a new circumstance

A J Crisp, MRCP, and Kathleen $M$ Sherry, MB................ 1438

Mefenamic acid poisoning and epilepsy

R H Robson, MRCP, and others . . . . . . . 1438

Penis captivus

W A Boekelman, MD . . . . . . . . . . . 1438

Antenatal prediction of fetal sex

M R Fell, FRCOG............... 1439

Screening for thyroid dysfunction in

diabetics

R S Gray, MRCP, and others; J Feely, MRCPI, and T E Isles, PHD . . . . . . . . . 1439

Diagnosis of multiple pregnancy

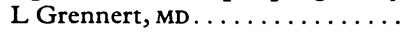

Disinfection with glutaraldehyde

R M G Boucher, PHD . . . . . . . . . . . 1440

The concept of disease

S R Wilkinson, MRCPSYCH........... 1440

Anaesthesia

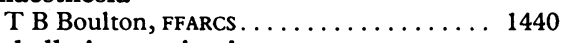

Rubella immunisation

Ruth P Ellman, MRCP... . . . . . . . . . . 1440

Weight penalties

$\mathrm{R}$ W Parnell, FRCP . . . . . . . . . . 1441
Clinical practice and community medicine

J I Mann, DM; J R Ashton, MFCM; U P

Seidel, MRCPSYCH.............. 1441

Professionai standards for consultant appointments

M M Sharr, FRCS . . . . . . . . . . . . . 1441

Multidisciplinary teams

A M Drayson, MRCPSYCH; H B Valman,

FRCP $\ldots \ldots \ldots \ldots \ldots \ldots \ldots \ldots \ldots \ldots 1442$

Payment for general practitioners in

hospitals

C J G Menzies, MrCGP . . . . . . . . . . . 1442

Cuts in NHS expenditure

A B Shrank, FRCP.......

Shortage of midwives

R W Burslem, FRCOG .......... 1442

Purchase of added years

J $M$ Smith, FRCPED . . . . . . . . . . . . . 1443

Points Analgesia and the acute abdomen (J

V Piper); Blood pressure measurement (S

Goldwater; $T$ H Hughes-Davies); A mild traumatic lesion (G L Bolt); Infertility (S K Goyal); "Wednesday's Child" (Mary Newns); Unwanted journals (R F B Lees); The Royal

Army Medical Corps (Major-General M H P

Sayers); If I was forced to cut ( $R T$ D

Fitzgerald $) \ldots \ldots \ldots \ldots \ldots \ldots \ldots \ldots \ldots 1443$

We may return unduly long letters to the author for shortening so that we can offer readers as wide a selection as possible. We receive so many letters each week that we have to omit some of them. Letters must be signed personally by all their authors. We cannot acknowledge their receipt unless a stamped addressed envelope or an international reply coupon is enclosed.

\section{Intravenous $\mathrm{N}$-acetylcysteine: the treatment of choice in paracetamol poisoning?}

SIR,-Our attention has been drawn to the article by $\operatorname{Dr} L$ F Prescott and others (3 November, p 1097), not least by its arresting title. We have long been resigned to this type of "question-begging" caption in the popular and more sensational press; but we must confess to some surprise at the adoption of this device in your journal, when we had adhered to the belief that in a scientific paper the facts should be presented impartially for the enlightened and discriminating reader to draw his own conclusions. You must forgive us, then, for putting the question mark in the heading of this letter.

It happens that we have detailed information on 132 patients with acute paracetamol poisoning treated with oral methionine, the details of which have been presented elsewhere. ${ }^{1}$ All of them on admission had plasma concentrations of the drug above a line joining semilogarithmic plots of $200 \mathrm{mg} / \mathrm{l}$ at 4 hours and $70 \mathrm{mg} / \mathrm{l}$ at 12 hours - that is, those who prognostically, on the basis of the figures in previous paper by Prescott et al,2 should have been destined for severe hepatotoxicity. Of these, 96 were given the oral methionine within 10 hours of ingestion and none died from hepatic failure (see accompanying table). Seven did suffer severe liver damage (aspartate transaminase $>1000 \mathrm{IU} / \mathrm{l}$ ), but six of these patients had extremely high paracetamol levels ( $>300 \mathrm{mg} / \mathrm{l}$ at 4 hours and $>75 \mathrm{mg} /$ at 12 hours).

When, on the other hand, the administration of the oral methionine was delayed beyond 10 hours from the time of paracetamol ingestion severe hepatic damage did ensue in 17 of these 36 patients, the outcome in this group being similar to that observed in the 57 patients studied retrospectively by $\mathrm{Dr}$ Prescott and his colleagues who had received supportive therapy only. So, as with other specific antidotes for this condition, including intravenous $\mathrm{N}$-acetylcysteine, the time interval still seems to be critical. We do suggest therefore that, to judge from our results, oral methionine-as distinct from the intravenous methionine with which Dr Prescott and his colleagues drew their comparisons-is just as effective as intravenous $N$-acetylcysteine in the treatment of acute paracetamol poisoning.

So there remains the question of adverse reactions and toxicity. Dr Prescott and his colleagues, in their present paper, claim that "frequent vomiting has been described with oral methionine" and cite a particular report, ${ }^{3}$ which on scrutiny refers to a single patientwho, it happens, survived quite satisfactorily despite the vomiting. In our series of 132 patients, $16 \%$ did vomit prior to the first dose of methionine, though only $5 \%$ continued to do so after the antidote; two of the patients among these did develop severe liver damage, possibly because they failed to absorb sufficient of the protective agent. It would seem reasonable therefore to give intravenous $N$-acetylcysteine rather than an oral preparation to all patients who vomit intractably.

Again, Dr Prescott and his colleagues say that methionine may be toxic. In this context they quote four references. On perusal one

Incidence of hepatic and renal damage in patients poisoned with paracetamol treated with methionine, cysteamine, and $N$-acetylcysteine

\begin{tabular}{|c|c|c|c|c|}
\hline Treatment group & $\begin{array}{c}\text { No of } \\
\text { patients }\end{array}$ & $\begin{array}{c}\text { No }\left(\begin{array}{c}0 \\
0\end{array}\right) \text { with severe } \\
\text { liver damage } \\
(A S T>1000 \text { IU } / 1)\end{array}$ & $\begin{array}{l}\text { No }(\%) \text { with acute } \\
\text { renal failure }\end{array}$ & No $(\%)$ of deaths \\
\hline 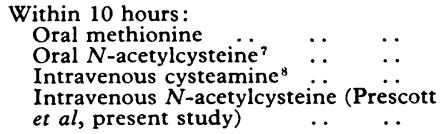 & $\begin{array}{l}96 \\
49 \\
23 \\
62\end{array}$ & $\begin{array}{l}7(7) \\
8(17) \\
0 \\
1(2)\end{array}$ & $\begin{array}{l}1(1) \\
0 \\
0 \\
0\end{array}$ & $\begin{array}{l}0 \\
0 \\
0 \\
0\end{array}$ \\
\hline 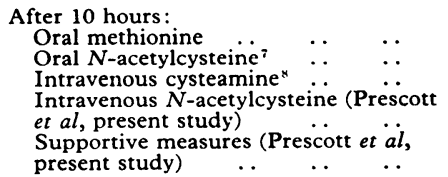 & $\begin{array}{ll}\cdots & 36 \\
\cdots & 51 \\
\cdots & 13 \\
\cdots & 38 \\
\ldots & 57\end{array}$ & $\begin{array}{r}17(47) \\
23(45) \\
8(62) \\
20(53) \\
38(58)\end{array}$ & $\begin{array}{l}2(5) \\
0 \\
1(8) \\
3(15) \\
6(17)\end{array}$ & $\begin{array}{l}2(5 \cdot 5) \\
0 \\
1(8) \\
1(5) \\
3(6)\end{array}$ \\
\hline
\end{tabular}


of them, ${ }^{4}$ we suggest, is irrelevant and another two, from signatories to this letter, ${ }^{5}{ }^{6}$ did in honesty mention this as a possibility without substantiating it with any evidence. In fact, in all our work with oral methionine in paracetamol poisoning we have never found any toxicity from it whatsoever.

In conclusion, we are happy to leave it to your readers to make up their own minds on the facts before them. After all, it is almost a question of "you pays your money and takes your choice." In these days of economic stringency, above all in the National Health Service, it might be worth mentioning that the course of oral methionine that we recommend in these circumstances will attract a charge of some $80 p$ whereas the corresponding course of $\mathrm{N}$-acetylcysteine as a "special intravenous preparation (Parvolex, Duncan Flockhart)" will cost more than $£ 30$.

J A VAle

T J MEREDITH

P CROME

M Helliweli

$\mathrm{G} N$ Volans

B WIDDOP

R GouldiNG

Poisons Unit,

Guy's Hospital,

' Vale, J A, Meredith, T J, and Goulding, R, Archives of Internal Medicine, suppl, in press.

'Prescott, L F, et al, Lancet, 1971, 1,519.

Medical Association, 1977, 70, 448.
Hardwick, D F, et al, Metabolism, 1970, 19, 381.

Meredith, T J, Newman, B, and Goulding, R, British Medical fournal, 1978, 2, 478.

Crome, P, et al, Lancet, 1976, 2, 829.

Rumack, B H, and Peterson, R G, Pediatrics, 1978

62, suppl, p 898.
$\times$ Prescott, L F, et al, Lancet, 1976, 2, 109.

\section{Monitoring of psychotropic drug prescribing in general practice}

SIR,-In his article on monitoring psychotropic drugs Dr P J Dennis makes the strong plea that "If repeat prescribing is carried out in a practice, then a facility for reassessment of treatment should be incorporated" ( 3 November, p 1115). He suggested a system using a repeat prescribing card for each patient as one method of achieving this.

The Birmingham research unit of the Royal College of General Practitioners is developing a programme of practice activity analyses and one of these concerns psychotropic drug prescribing. In the preliminary trials of this recording instrument, which involved abou 100 general practitioners, the percentage distribution of psychotropic drug usage was simila to that in Dr Dennis's study. Eighteen per cent of the total psychotropic drug prescriptions were new prescriptions given at face-toface consultations, and $36^{\circ}$ \% were issued during consultations concerned with continuing management. ${ }^{1}$ The residual $46^{\circ}{ }_{0}$ were repeat prescriptions given without consultation with a doctor. However, these average rates hide an enormous range of variability between differen recorders. We would suggest that the RCGP practice activity analysis form, available from the Birmingham research unit, is an economic and simple way of establishing for any genera practitioner his personal pattern of prescribing of psychotropic drugs.

Finally, it may well be that reliance on selfreferral by elderly patients is misplaced, but this was not established by Shaw and Opit's study. ${ }^{2}$ We have questioned the value and relevance of this study elsewhere. ${ }^{34}$

\section{L CRombie}

Royal College of General

Practitioners General

Practice Research Unit,

1 Royal College of General Practitioners, Birmingham Research Unit, fournal of the Royal College of General Practitioners, 1978, 28, 122.

Shaw, S M, and Opit, L J, British Medical fournal, $1976,1,505$.

Fournal of the Royal College of General Practitioners, Crombie, D L, et al, British Medical fournal, 1976, 1, 713 .

\section{Perinatal epidemiology in Wonderland}

SIR,-Professor Leiv S Bakketeig and $\mathrm{Mr}$ Howard J Hoffman (22 September, p 693) have analysed the data on the Norwegian linked file in what they claim to be a more meaningful way than the traditional crosssectional method. They showed that if the rate of fetal death is plotted for each pregnancy rank, according to the total number of pregnancies the woman eventually has, the risk to each succeeding pregnancy falls. This method had actually been demonstrated and discussed earlier by James ${ }^{12}$ and Billewicz."

As Professor Nathan Mantel pointed out (3 November, p 1147), such a method is introducing enormous bias in that it is the woman herself who has the main choice in the number of pregnancies she has. The woman who has a fetal loss is far more likely to keep trying-until she has one or more successes. On the other hand, the woman who starts with one or two successes is then likely to stop reproducing.

The disturbing feature of the Norwegian paper is that the data have been interpreted by others in this country as indicating that for any individual woman the risk of fetal death decreases with successive pregnancies. It is this thesis in particular that I wish to dispute.

Given a group of pregnant women, even the most intuitive clinician is unlikely to be able to determine how many pregnancies the woman will eventually have, and thence which line of the accompanying figure she will be following. What he will know is how many pregnancies she has already had, and what their outcome was. The data from the 1958 survey $^{4}$ show that even when the woman has had no previous stillbirths or neonatal deaths the risk of such an outcome to the current pregnancy rises from parity 1 to parity 4 or more (see accompanying table). In other words, given limited resources the clinician should still concentrate them in the traditional manner (that is, on women having their first pregnancy and on women of high parity).

Rate (per 1000) of stillbirth and neonatal death by parity and previous history, with number of deaths in parentheses (1958 British Perinatal Mortality Survey ${ }^{4}$ )

\begin{tabular}{|c|c|c|c|}
\hline \multirow[b]{2}{*}{ Parity } & \multicolumn{2}{|c|}{ Previous history } & \multirow[b]{2}{*}{ All } \\
\hline & $\begin{array}{c}1 \text { or more } \\
\text { stillbirths or } \\
\text { neonatal deaths }\end{array}$ & $\begin{array}{l}\text { No stillbirths } \\
\text { or neonatal } \\
\text { deaths }\end{array}$ & \\
\hline $\begin{array}{r}0 \\
1 \\
2 \\
3 \\
4 \\
5-6 \\
7+\end{array}$ & $\begin{array}{ll} & \\
70.4 & (168) \\
67.1 & (228) \\
77.5 & (159) \\
85.5 & (118) \\
91.1 & (129) \\
59.0 & (126)\end{array}$ & $\begin{array}{rr}37 \cdot 0 & (2793) \\
24 \cdot 1 & (1450) \\
30 \cdot 8 & (875) \\
33 \cdot 4 & (463) \\
40 \cdot 4 & (272) \\
43 \cdot 6 & (250) \\
103 \cdot 8 & (81)\end{array}$ & $\begin{array}{l}37 \cdot 0(2793) \\
25 \cdot 9(1619) \\
34 \cdot 7(1104) \\
39 \cdot 1 \quad(622) \\
48 \cdot 1(390) \\
52 \cdot 9(379) \\
71 \cdot 0 \quad(207)\end{array}$ \\
\hline
\end{tabular}

How then has this paradox been produced? Lewis Carroll would have enjoyed teasing out the answer. I would like to stress what I consider to be the salient factors. Basically women desire families with living children. Thus the total number of pregnancies to women who started their reproductive life with a perinatal loss will be greater than the total number of pregnancies to women with successful first pregnancies. A combination of the two groups produces the extraordinary picture shown in the figure.

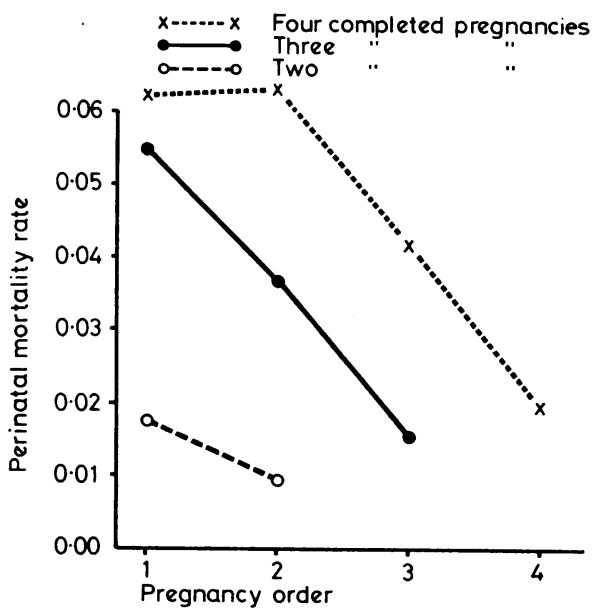

Perinatal mortality rate according to total number of pregnancies (adapted from Bakketeig and Hoffman).

More detailed evidence that such a picture can be produced in the way I have suggested has been submitted for publication. Meanwhile, it would be a pity if clinicians and epidemiologists alike were to consider the analysis by Professor Bakketeig and $\mathrm{Mr}$ Hoffman as anything other than an amusing artefact.

National Perinatal

Epidemiology Unit,
Oxford OX3 8DR

James, $\mathrm{W}$, Annals of Human Genetics, London 1968, 32, 151 .

2 James, W H, Journal of the Royal Statistical Society Series $C, 1969,18,276$.

Billewicz, W Z, British Journal of Preventive and Social Medicine, 1973, 49, 27.

Butler, N R, and Bonham, D G, Perinatal Martality The First Report of the British Perinatal Mortalit

SIR,-For some years it has been recognised that attempts to relate risk of pregnancy loss or immaturity to maternal age, parity, or birth interval, based on cross-sectional studies, are of limited value in view of the powerful confounding artefact effects relating principally to the ability of women to exercise a measure of choice in the matter of whether and when to initiate a pregnancy. MrN Mantel (3November, p 1147) has exposed a flaw in the argument of Professor Leiv Bakketeig and Mr H J Hoffman (22 September, p 693), who have aimed to compensate for the artefacts by a longitudinal approach.

Clearly the problem of how to estimate the true underlying dependence of risk on birth order is not trivial. A sequential approach seems indicated. It is desirable to have data on entire reproductive histories, and a set of data from which an appropriate analysis may readily be recovered was published by Roman et $a l,{ }^{1}$ whose study is quoted in the present 